\title{
Faculty Ways of Knowing, Valuing, and Assessing Leadership in the Under- graduate Engineering Curriculum
}

\section{Dr. Cassandra J. Groen, Virginia Tech}

Dr. Cassandra Groen is a post-doctoral researcher in the Department of Engineering Education and the Myers-Lawson School of Construction at Virginia Tech. Her primary research interests include professional identity formation in undergraduate civil engineering students, grounded theory methods, and theory development. Her current work includes the exploration of professional identity formation in civil engineering students who experience disabilities and the ways in which this identity is influenced by students' academic relationships, events, and experiences. Dr. Groen holds B.S. and M.S. degrees in Civil Engineering from the South Dakota School of Mines \& Technology.

\section{Dr. Denise Rutledge Simmons P.E., Virginia Tech}

Denise R. Simmons, Ph.D., PE, LEED-AP, is an assistant professor in the Myers-Lawson School of Construction and in the Department of Civil \& Environmental Engineering, and an affiliate faculty of the Department of Engineering Education at Virginia Tech. She holds a B.S., M.S., and Ph.D. in civil engineering and a graduate certificate in engineering education - all from Clemson University. She has over 10 years of experience working for energy companies and as a project management consultant. Her research contributes to the advancement of labor and personnel issues in engineering broadly and specifically in the construction industry through two research areas: untangling the complex relationship between activities people become involved in - operationalized as engagement - and the technical and professional outcomes gained - operationalized as competencies. The broader impact of this work lies in achieving and sustaining productive, diverse and inclusive project organizations composed of engaged, competent people. Dr. Simmons' research is supported by awards from NSF, including a CAREER award. She oversees the Simmons Research Lab (www.denisersimmons.com), which is home to a dynamic, interdisciplinary mix of undergraduate and graduate students and a post-doctoral researcher from various colleges and departments at Virginia Tech who work together to explore engineering and construction human centered issues with an emphasis on understanding difference and disparity.

Dr. Nicholas Anthony Clegorne 


\section{Faculty Ways of Knowing, Valuing, and Assessing Leadership in the Undergraduate Engineering Curriculum}

\section{Background}

Prior research has shown that entering college students typically maintain unclear expectations of engineering work [1]. For these students, faculty often serve as arbiters of disciplinary knowledge by delivering and translating skills, information, and discourse necessitated by engineering industry. Through pedagogical practices, assessment strategies, and course content, faculty inherently communicate to students what are considered to be valued skills and knowledge in engineering, demonstrating to them who engineers are and what engineers do [2, 3].

In mathematically-based fields such as engineering, skills and knowledge tend to be skewed toward many of the technical competencies, which are well-defined, easily-conceptualized, and commonplace within engineering courses [3-5]. However, the skills and knowledge not discussed in the undergraduate engineering classroom also inherently speak volumes about competency importance and relevance to the engineering field. Professional skills, such as leadership, are often ill-defined, complex, and misunderstood, leaving many faculty to place little to no emphasis on these topics. Therefore, students tend to generally perceive technical competencies as more valuable for emerging engineers, often positioning technical competence as "real" engineering work; in turn, professional skills are typically perceived to be less valuable and not directly related to engineering [3].

The paucity of leadership education in undergraduate engineering curricula points to deeper concerns surrounding faculty training. Faculty in higher education typically receive little to no formal training to teach [6], making ill-defined competencies such as leadership difficult to implement and assess within formal educational settings. In engineering education, faculty have reported feeling unprepared to teach upon entering their academic positions [7] with only $15 \%$ reporting attending a teaching program during graduate school [8-10]. Due to this lack of training, many faculty typically rely on the pedagogical approaches utilized by their instructors in their own courses, thus perpetuating a signature pedagogy within engineering [6]. Shulman describes signature pedagogies as "important precisely because they are pervasive. . . they implicitly define what counts as knowledge in a field and how things become known" [6, p. 54]. In fields such as engineering, the signature pedagogy tends toward mathematically-based assessments of key engineering concepts such as statics, heat transfer, and deforms. However, the mathematically-based signature pedagogy of engineering does not necessarily align with the signature of the engineering profession itself [6]. Therefore, as engineering education experiences increased demands to implement professional skill development within their curricula [11-15], faculty are pressed to integrate technical and professional competency development and leave the familiarity of engineering signature pedagogy while lacking the resource and training support to do so.

To begin to develop these support structures for faculty and gain a greater understanding of leadership as an educational construct, it is necessary to understand how faculty currently translate, value, and communicate this construct to their undergraduate students. In this paper, 
we seek to gain an initial understanding of the intersections of faculty knowledge and value of engineering leadership by asking the overarching research question: How do faculty come to know leadership within engineering education? As part of a larger study exploring definitions of leadership across students, faculty, and industry professionals, the results from this analysis - as well as findings that warrant further inquiry - will be used to develop a semi-structured interview protocol to guide faculty interviews in subsequent phases of the larger project.

\section{Conceptual Framework: Faculty Ways of Knowing}

To gain a deeper understanding of the ways in which faculty come to know leadership within engineering education, we examine the sources from which faculty acquire, experience, and communicate leadership knowledge in engineering through a conceptual framework of faculty ways of knowing. Initially, educational ways of knowing were conceptualized as the understanding of the extent of an educator's content knowledge [16]. However, multiple scholars challenged this notion, emphasizing that content knowledge does not necessarily translate into better teaching [16], nor does it capture ways in which faculty obtain, value, and communicate that knowledge [6]. As such, we draw on literature in education [16, 17], social identity [18, 19], and teacher/faculty identity [20,21] to conceptualize ways of knowing as not only the amount of leadership knowledge acquired by a faculty member, but also as the beliefs, values, and experiences that underpin the ways in which faculty construct, translate, and communicate that knowledge to students as a member of the engineering profession. As illustrated in Figure 1, our conceptual framework encompasses four dimensions of faculty ways of knowing: 1) teaching, 2) assessment, 3) knowledge/awareness, and 4) attributed value.

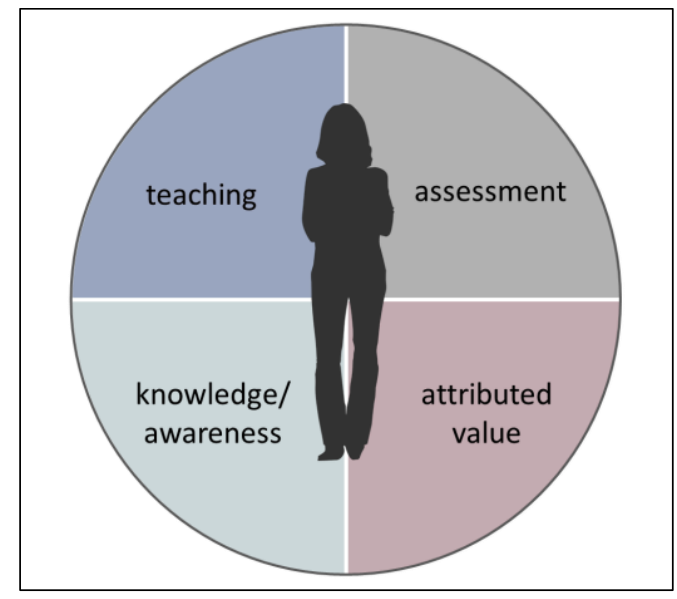

Figure 1: Conceptualizing faculty ways of knowing leadership

The first dimension, teaching, captures faculty perspectives regarding prior experience in teaching leadership within engineering courses as well as their views of and approaches to introducing leadership content to students. The second dimension, assessment, examines faculty beliefs regarding the ways in which leadership can or should be assessed within engineering curricula. The third dimension, knowledge/awareness, begins to identify the sources from which faculty learn about leadership and their awareness of the prevalence of leadership within the industry of their associated discipline. Last, the attributed value dimension examines the value that faculty place on various aspects of leadership competencies as necessitated by engineering 
industry. From these perspectives, these dimensions capture how faculty acquire and internalize leadership knowledge and the ways in which it is enacted within the classroom.

\section{Methods}

The methods for this exploratory work are drawn from a larger, multi-institutional mixed methods study examining definitions of leadership from the perspectives of industry, faculty, and students in order to identify common understandings and misconceptions across groups. For the purpose of this paper, we focus on faculty perspectives and pedagogical practices to gain an initial understanding of how they conceptualize leadership within undergraduate engineering education. In particular, we qualitatively examine survey responses to explore the ways in which faculty teach, assess, value, and come to know about leadership as situated within the undergraduate engineering curriculum. Findings will then be used to inform subsequent faculty interviews that will be conducted to further examine this topic.

\section{Data Collection}

As part of a larger, mixed methods study, an online survey was developed using Qualtrics survey software. The faculty portion of the survey consisted of 13 items that were developed by the research team and informed by consultations with the project advisory board, prior literature [24], and the team's prior work experiences in academia and industry. While survey items included topics such as course background and content specialty, we focused our analysis here on responses to survey items that align with the conceptual framework dimensions (Figure 1) to reveal inherent faculty perceptions regarding content, importance, and assessment of leadership in the engineering curriculum. Characteristics of the survey items explored with their corresponding dimensions are shown in Table 1.

Table 1: Selected survey items (as worded within the larger survey)

\begin{tabular}{|c|c|c|}
\hline Dimension & Question Wording & Question Type \\
\hline \multirow[t]{2}{*}{ Teaching } & $\begin{array}{l}\text { T1: What year do you think is most appropriate for students to be introduced to } \\
\text { leadership competencies within the curriculum? }\end{array}$ & Select Answer \\
\hline & $\begin{array}{l}\text { T2: For any of the courses you currently teach or formerly taught, is any aspect } \\
\text { of leadership (i.e., concepts, competencies, outcomes) included? }\end{array}$ & Select Answer \\
\hline Assessment & $\begin{array}{l}\text { A1: Evaluation of leadership competencies within coursework should be: test- } \\
\text { based, project-based, both test- and project-based, none, or other. }\end{array}$ & Select Answer \\
\hline \multirow[t]{2}{*}{$\begin{array}{l}\text { Knowledge/ } \\
\text { awareness }\end{array}$} & $\begin{array}{l}\mathrm{K} 1: \text { I know the importance companies that employ graduates from my } \\
\text { institution place on leadership. }\end{array}$ & Select Answer \\
\hline & $\begin{array}{l}\text { K2: How did you come to know and understand the importance companies that } \\
\text { employ your graduates place on leadership? }\end{array}$ & Short Answer \\
\hline \multirow[t]{3}{*}{ Attributed value } & $\begin{array}{l}\text { V1: With } 0 \text { meaning not important at all and } 100 \text { meaning highest importance, } \\
\text { rate your opinion of the importance of leadership application. }\end{array}$ & $\begin{array}{l}\text { Numeric Rating } \\
\text { Scale }\end{array}$ \\
\hline & $\begin{array}{l}\text { V2: With } 0 \text { meaning not important at all and } 100 \text { meaning highest importance, } \\
\text { rate your opinion of the importance of leadership competence. }\end{array}$ & $\begin{array}{l}\text { Numeric Rating } \\
\text { Scale }\end{array}$ \\
\hline & $\begin{array}{l}\text { V3: With } 0 \text { meaning not important at all and } 100 \text { meaning highest importance, } \\
\text { display the level of importance you believe each competency has in the industry } \\
\text { where most of your graduates become employed. }\end{array}$ & $\begin{array}{l}\text { Numeric Rating } \\
\text { Scale }\end{array}$ \\
\hline
\end{tabular}


As shown in Table 1, survey questions were developed using multiple question types that prompted respondents to select an answer, identify a rating using a numeric scale, or write-in a short response. Items requiring a numerically-rated response were used to identify levels of value faculty placed on leadership within the undergraduate engineering curriculum. For all items, an "other" option was provided to capture any unanticipated responses. In the event that a participant selected "other" as their response, they were also prompted to briefly clarify this response using a short answer text entry.

The survey was distributed to six undergraduate engineering schools/colleges across the U.S. All participating universities were large, public institutions that ranged from undergraduate-focused to research-intensive. Overall, a total of 40 faculty members responded to the survey who taught a variety of engineering-related courses ranging from introductory engineering and mathematics courses to upper-level senior design and professional development. A distribution of course specialties reported by respondents are presented in Figure 2.

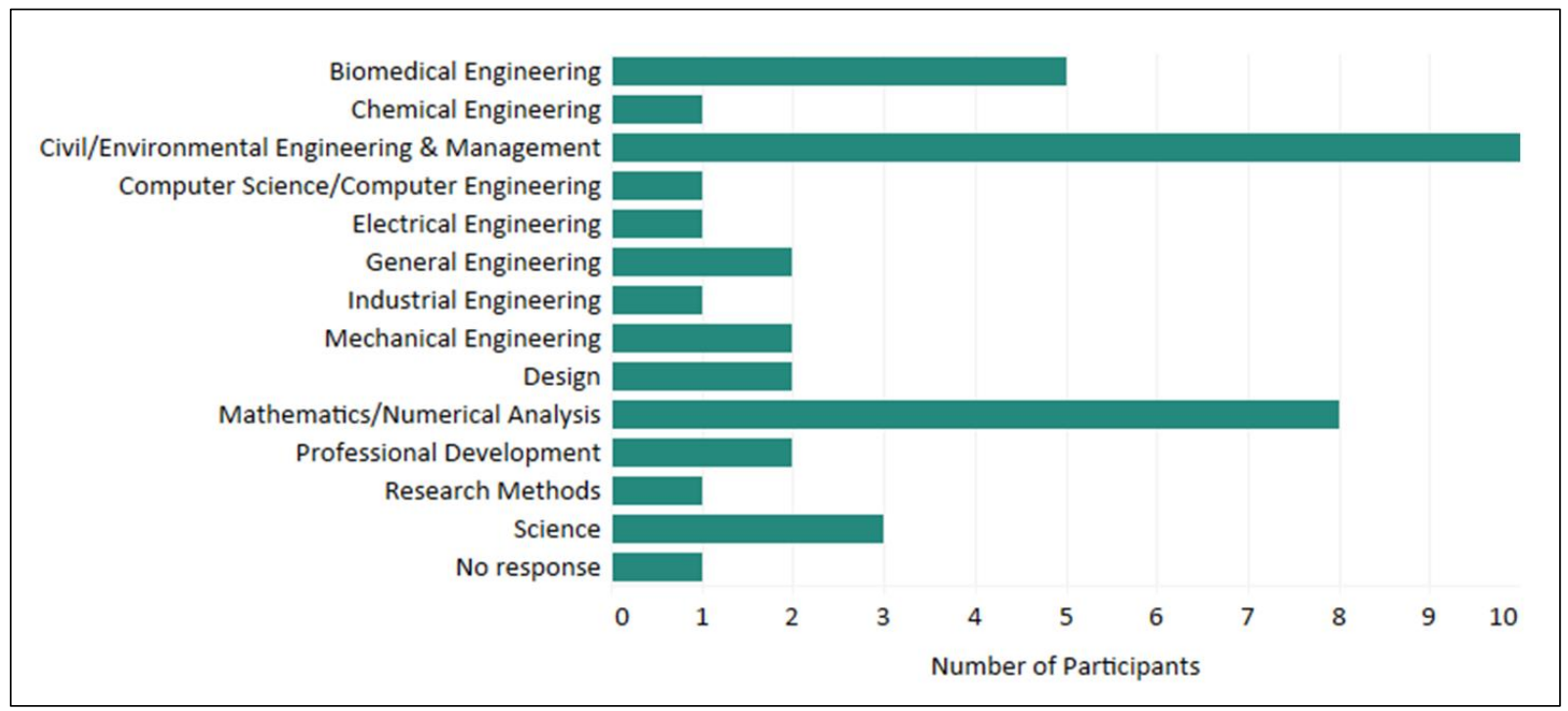

Figure 2: Respondent breakdown according to reported course specialty

\section{Data Analysis}

To gain an initial understanding of faculty perceptions of leadership in the engineering curriculum and develop protocols for subsequent faculty interviews, we conducted a qualitative analysis as informed by Charmaz [22] and Thomas [23]. A qualitative approach was utilized to analyze these data for two reasons. First, due to the low number of faculty responses to the survey $(\mathrm{N}=40)$, the research team could not quantitatively identify correlations or conclusions that could be generalized across faculty populations in undergraduate engineering programs. Second, as the purpose of this focused study is to explore how faculty conceptualize leadership and enact those perceptions through their pedagogical approaches, the research team wanted to explore the nuances among faculty responses to research items - particularly those indicated in the "other," short answer prompts in the survey. Due to the qualitative nature of the optional prompts, in addition to responses to short-answer items such as K2 (i.e., identify source of leadership knowledge), a qualitative analysis enabled the research team to examine themes 
across survey responses that related dimensions of faculty teaching approaches, assessment strategies, knowledge and awareness, and value of leadership. To glean further nuance from survey responses, negative cases [23] were examined within identified themes. Inspired by the grounded theory underpinnings of the qualitative portion of the larger study [16, 23], negative cases are data that sharply contrast emerging themes that are accounted for in the majority of the data [23]. For this focused study discussed within this paper, the use of negative cases were particularly valuable for further developing our interview protocol to be used in subsequent phases of the larger study; they tested the robustness of our developing propositions and compelled us to ask further questions of the data that we may not have otherwise examined. The negative cases identified in this study are further described in the Results and Discussion section.

During this initial coding process, a priori codes were combined with emergent codes to identify clusters of faculty ways of knowing leadership in engineering curricula. A priori codes consisted of selected qualitative responses from an item's provided list of options. Emergent codes were developed from short-answer items such as $\mathrm{K} 2$, in which participants were asked to identify the source through which their leadership knowledge was acquired. A summary of the emergent codes for question $\mathrm{K} 2$ is presented in Table 2.

Table 2: Emergent codes for source of leadership knowledge (item K2)

\begin{tabular}{|c|c|c|}
\hline Source & Definition & Example Response \\
\hline $\begin{array}{l}\text { Program Advisory } \\
\text { Board }\end{array}$ & $\begin{array}{l}\text { The participant learned about leadership by speaking with } \\
\text { members of or participating on a Program Advisory } \\
\text { Board. }\end{array}$ & $\begin{array}{l}\text { "From meetings with my } \\
\text { academic program's advisory } \\
\text { board members." (P2) }\end{array}$ \\
\hline External Board & $\begin{array}{l}\text { Learning about leadership by speaking with members of } \\
\text { an advisory board outside of academia. }\end{array}$ & "Outside board." (P7) \\
\hline $\begin{array}{l}\text { Professional } \\
\text { Contacts }\end{array}$ & $\begin{array}{l}\text { Learning about leadership through professional } \\
\text { connections within industry such as past students/alumni, } \\
\text { industry contacts, job recruiters, or other industry } \\
\text { representatives. }\end{array}$ & $\begin{array}{l}\text { "Personal contact at career fairs } \\
\text { or via phone conversations." } \\
\text { (P16) } \\
\text { "Previous students." (P25) }\end{array}$ \\
\hline Hearsay & $\begin{array}{l}\text { Learning about leadership by overhearing conversations } \\
\text { or engaging in informal conversations. }\end{array}$ & $\begin{array}{l}\text { "Informal conversations." (P19 } \\
\text { \& P34) }\end{array}$ \\
\hline Work Experience & $\begin{array}{l}\text { The importance of leadership was learned through the } \\
\text { instructor's prior work experience in industry. }\end{array}$ & $\begin{array}{l}\text { "I worked in the chemical } \\
\text { industry for } 35 \text { years." (P10) }\end{array}$ \\
\hline Graduate School & $\begin{array}{l}\text { Participant learned about leadership during their tenure in } \\
\text { graduate school. }\end{array}$ & $\begin{array}{l}\text { "Mainly graduate school." } \\
\text { (P37) }\end{array}$ \\
\hline Personal Opinion & $\begin{array}{l}\text { It is the personal opinion of the participant that leadership } \\
\text { is important. }\end{array}$ & "Personal opinion.” (P5) \\
\hline Research & $\begin{array}{l}\text { Learning about leadership through personal research such } \\
\text { as reading articles or examining research data. }\end{array}$ & "I read about it." (P13) \\
\hline
\end{tabular}

The analysis was completed in three phases. Phase 1 consisted of developing emergent codes for short answer items such as Item K2 and "other" short answer prompts. During Phase 2, participant responses were compared and clustered across questions within each observed dimension to identify emergent patterns of faculty teaching, knowledge, and value. For example, for the knowledge/awareness dimension, items were compared to identify patterns among faculty 
awareness of the value industry places on leadership (item K1) and the source from which faculty learned about leadership (item K2). Notably, this analysis was not conducted for the assessment dimension, as there was only one item allocated to that dimension. In Phase 3, patterns identified in Phase 2 were further examined across dimensions to explore potential overarching themes in faculty ways of knowing leadership. For example, items related to knowledge/awareness were compared to those belonging to the teaching and assessment dimensions. In the following sections, we discuss key observations resulting from this analysis and their implications for ongoing work.

\section{Results \& Discussion}

As a result of the baseline analysis for this study, an initial profile of faculty ways of knowing was developed. In general, faculty claimed to be moderately knowledgeable about the importance industry places on leadership (40\%), often gaining that knowledge through their professional contacts in industry $(35 \%)$ and by working with external or industry advisory boards within their programs (28\%). While the majority of faculty reported that they do not incorporate leadership in their own courses $(60 \%)$, they generally feel that leadership should be introduced during a student's freshman year of college (40\%) and evaluated using project-based assessments or a combination of test- and project-based assessments $(80 \%)$. Overall, faculty tended to agree with industry on the importance of leadership competencies in their associated fields, particularly for competencies such as ethics/responsibility, communication, professionalism, and ambition.

But while this overall profile generically captures faculty ways of knowing leadership among survey respondents, our analysis also uncovered nuances within the data that warrant further exploration as highlighted by identified negative cases. While $40 \%$ of faculty reported that leadership should be introduced during a student's freshman year of college, none of these faculty claimed to be "extremely knowledgeable" about the importance industry places on leadership in their given fields. For those faculty reporting to be extremely or very knowledgeable of leadership in industry, responses to item T1 (i.e., year of introduction) varied from freshman year to senior year with four faculty (10\%) selecting the "N/A: leadership competencies should not be a curricular element" option. These responses brought about questions regarding the relationship between the knowledge/awareness and teaching dimensions of faculty ways of knowing; how does knowledge/awareness of leadership in industry influence faculty perceptions regarding the location - or absence - of teaching leadership within undergraduate engineering curricula?

Similarly, as another negative case, a faculty member expressed their view of an unwarranted role of leadership in engineering curricula. In response to item A1 (i.e., appropriate assessment techniques), the participant stated, "Leadership should be assessed by other leaders and not part of the grade for a course. Grades (in the current culture of students) do not resonate with 'leadership'. The closest one should get to a grade is through specific communication aspects of courses." In the faculty's response, they state that "leadership should be assessed by other leaders, (emphasis added)" bringing into question the faculty role within developing students' technical content knowledge as well as professional competencies: Do faculty see leadership education as part of their role as an educator or do they perceive themselves as primarily responsible for teaching technical content? Further, the same participant stated that "grades (in 
the current culture of students) do not resonate with 'leadership' (emphasis added)," which raises additional questions regarding faculty perceptions of the current assessment strategies typically used in engineering courses.

Further discrepancies and nuance were identified when comparing faculty responses rating the importance of industry-identified competencies. While all faculty aligned with industry regarding the importance of professional competencies such as ethics, communication, and professionalism, we began to see some faculty responses diverge from general industry perspectives regarding the development of competencies such as employee assertiveness; leadership; learning, discovery, and research; legal knowledge; and economic principles and trends (shown in Figure 3). One faculty, in particular, reported being slightly knowledgeable about the importance industry placed on leadership, and aligning with findings from $[8,10]$ and Shulman [6], identified graduate school as the primary source of his limited knowledge. For all competencies listed in Figure 4 (i.e., assertiveness, leadership, learning/discovery/research, legal knowledge, economic principles and trends), this participant rated them $16,17,15,8$, and 3 out of 100, respectively. The variation in faculty responses, as shown in Figure 3, prompted questions regarding the potential role and impact that faculty training, development, and support programs may have on faculty knowledge of leadership; the source(s) of prior faculty training; and the potential alignment between industry and academia regarding these competencies.

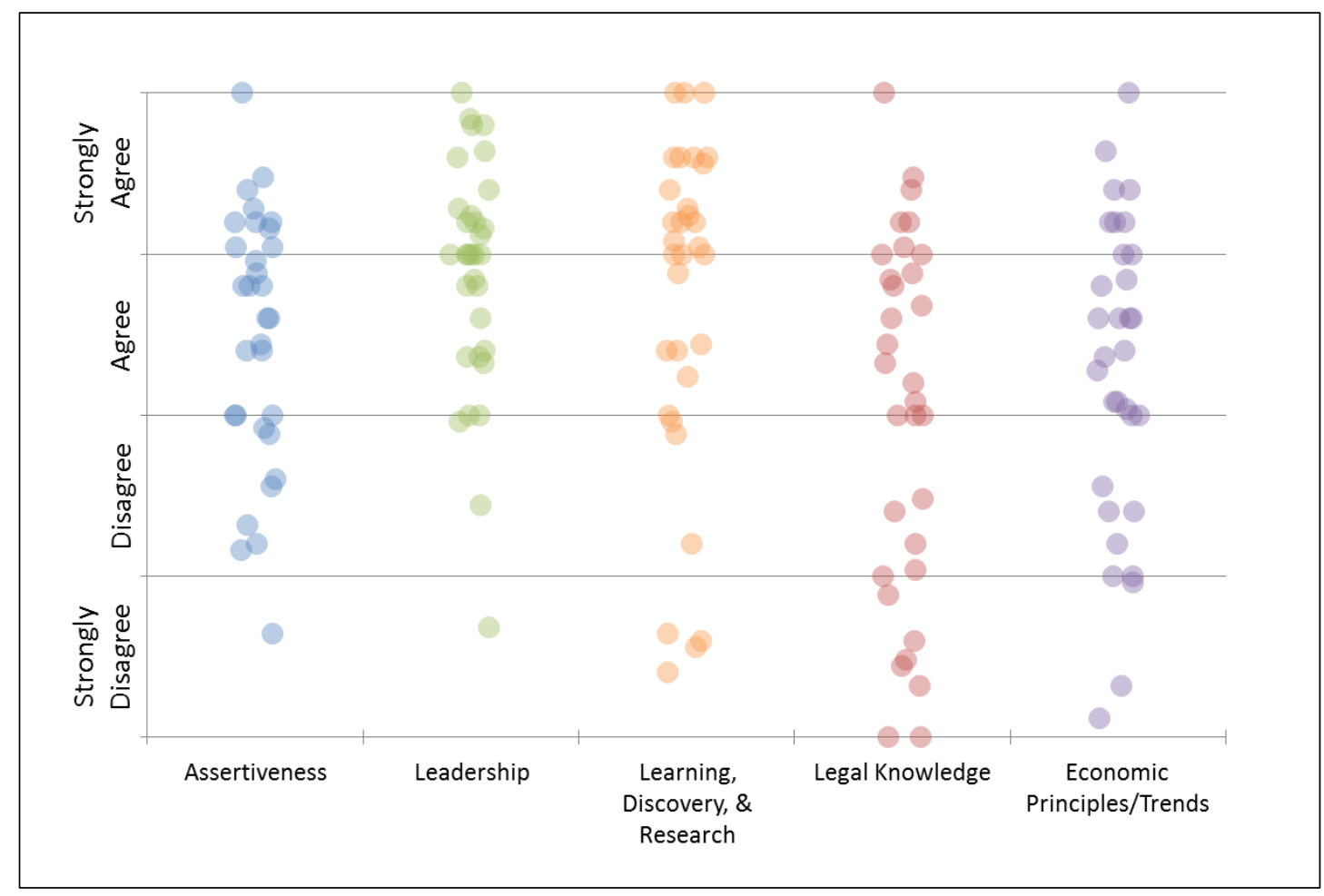

Figure 3: Faculty agreement with industry for selected competencies

We recognize that, as a qualitative data collection instrument, these survey responses were limited and devoid of context. However, aligning with our conceptual framework, we acknowledge that such responses are imbued with a variety of contextual factors such as university type (i.e., teaching versus research); prior experiences in industry and academia; and 
university, departmental, and disciplinary cultures. As such, these responses warrant further investigation regarding why these responses exist and their implications for faculty development programs and other training resources. Upon identifying points of contention of faculty ways of knowing leadership in undergraduate engineering curricula, these points can be used to inform a deeper and more intentional look into faculty experience, backgrounds, and beliefs, which can serve as a critical source for developing and implementing professional competencies such as leadership into undergraduate engineering courses.

\section{Future Work}

For the purpose of this study, we sought to gain a baseline foundation of faculty ways of knowing leadership within undergraduate engineering curricula. While we established a general profile of faculty ways of knowing, our analysis generated areas that require further exploration within the larger, ongoing mixed-methods study examining faculty definitions and conceptions of leadership. In particular, the results from this study bring into question the perceived role of faculty as leadership educators; perceptions of current assessment strategies present within engineering education; and prior training and leadership development. Exploring such topics may highlight potential impacts of faculty development and training programs and other sources of support - or lack thereof. The next phases of the larger research project include conducting interviews with faculty, which will include the protocol questions shown in Table 3.

Table 3: Original interview protocol to examine faculty definitions and perceptions of leadership in undergraduate engineering curricula

\begin{tabular}{|l|l|}
\hline Dimension & Question \\
\hline Teaching & $\begin{array}{l}\text { As an instructor, what do you do to prepare students for their future careers? } \\
\bullet\end{array}$ \\
\hline Assessment & $\bullet \quad \begin{array}{l}\text { Think about the outstanding seniors in your program. What separates them from their } \\
\text { peers? }\end{array}$ \\
\hline $\begin{array}{l}\text { Knowledge/ } \\
\text { awareness }\end{array}$ & $\bullet \quad \begin{array}{l}\text { Think about the outstanding seniors in your program. What separates them from their } \\
\text { peers? }\end{array}$ \\
\hline Attributed value & $\bullet \quad \begin{array}{l}\text { How would you define leadership in your field? } \\
\text { activities? What are the reasons for providing this advice? }\end{array}$ \\
\hline
\end{tabular}

As a result of this analysis, the following questions have been added to the existing interview protocol, shown in Table 4:

Table 4: Added questions to original protocol

\begin{tabular}{|l|cl|}
\hline Dimension & Question \\
\hline Teaching & $\bullet \quad$ What is your role in teaching students leadership during their undergraduate experience? \\
\hline Assessment & $\bullet \quad$ Can leadership be assessed? Why or why not? \\
\hline Knowledge/ & $\bullet \quad$ What is your prior training related to leadership? \\
awareness & $\bullet \quad$ How many years were you in industry prior to becoming a faculty member? \\
\hline Attributed value & $\bullet$ & How important is teaching leadership in STEM? \\
\hline
\end{tabular}




\section{Conclusion}

In this paper, we conducted an initial analysis to explore how faculty come to know about and perceive leadership in undergraduate engineering curricula. In particular, we examined four dimensions of faculty ways of knowing that included teaching, assessment, knowledge/awareness, and attributed value. Due to the qualitative nature of the short answer prompts within the survey, a qualitative analysis was conducted on survey responses from 40 faculty located within six engineering schools across the U.S. However, this analysis reveals more questions than answers. While an initial profile of faculty perceptions of leadership could be identified from the data, few patterns emerged that could serve as relational indicators across dimensions, revealing nuance among items that warrant further exploration. Subsequent interviews, as informed by this preliminary study, will further explore topics such as perceptions of faculty role in teaching leadership and effective sources of faculty leadership education and development; and contribute to ongoing conversations surrounding faculty beliefs and pedagogical content and practice.

\section{Acknowledgements}

The authors gratefully acknowledge the National Science Foundation for supporting this work under award no. 1463802. Any opinions, findings, conclusions, or recommendations expressed here are those of the authors and do not necessarily reflect the views of the National Science Foundation.

\section{References}

1. Stevens, R., A. Johri, and K. O’Connor, Professional engineering work, in Cambridge Handbook of Engineering Education Research, A. Johri and B.M. Olds, Editors. 2014, Cambridge University Press: Cambridge, MA. p. 119-138.

2. Dannels, D.P., Learning to be professional technical classroom discourse, practice, and professional identity construction. Journal of Business and Technical Communication, 2000. 14(1): p. 5-37.

3. Faulkner, W., Nuts and Bolts and People'Gender-Troubled Engineering Identities. Social studies of science, 2007. 37(3): p. 331-356.

4. Noble, D.F., Technology and the commodification of higher education. Monthly Review, 2002. 53(10): p. 302-317.

5. $\quad$ Pinar, W.F., What is curriculum theory? 2012: Routledge.

6. $\quad$ Shulman, L.S., Signature pedagogies in the professions. Daedalus, 2005. 134(3): p. 5259.

7. Huang, Y.-M., J.M. Yellin, and J. Turns. Future engineering faculty: How do they think about teaching? in 35th Annual meeting of the ASEE/IEEE Frontiers in Education Conference. 2005. Indianapolis, IN.

8. Lattuca, L.R., P.T. Terenzini, and J.F. Volkwein, Engineering change: A study of the impact of EC2000. 2006, Baltimore, MD: ABET, Inc. 1-20.

9. Lattuca, L., A. Yin, and I. McHale. Influences on engineering faculty members' teaching and beliefs about teaching. in Research paper presented at the 2010 Annual Conference of The Association for the Study of Higher Education, Indianapolis, IN. 2010. 
10. Lattuca, L.R., I. Bergom, and D.B. Knight, Professional development, departmental contexts, and use of instructional strategies. Journal of Engineering Education, 2014. 103(4): p. 549-572.

11. Spohrer, J. and S.K. Kwan, Service science, management, engineering, and design (SSMED): An emerging discipline. International Journal of Information Systems in the Service Sector, 2009. 1(3): p. 1-31.

12. Toor, S.-u.-R. and G. Ofori, Developing construction professionals of the 21st century: renewed vision for leadership. Journal of Professional Issues in Engineering Education and Practice, 2008. 134(3): p. 279-286.

13. Russell, J.S. and B. Stouffer, Leadership: Is it time for an educational change? Leadership and Management in Engineering, 2003. 3(1): p. 2-3.

14. Carrato, P. and R. Haryott, Building leaders of a global society. Journal of Professional Issues in Engineering Education and Practice, 2003. 129(3): p. 125-128.

15. Bonasso, S.G., Engineering, leadership, and integral philosophy. Journal of Professional Issues in Engineering Education and Practice, 2001. 127(1): p. 17-25.

16. Cooney, T.J., Conceptualizing teachers' ways of knowing. Educational Studies in Mathematics, 1999. 38(1/3): p. 163-187.

17. McKay, V.C. and P.D. Rozee, Characteristics of faculty who adopt community service learning pedagogy. Michigan Journal of Community Service Learning, 2004. 10(2): p. 21-33.

18. Tajfel, H., Social identity and intergroup behaviour. Social Science Information, 1974. 13(2): p. 65-93.

19. Spears, R., Group identities: The social identity perspective, in Handbook of Identity Theory and Research, S.J. Schwartz, K. Luyckx, and V.L. Vignoles, Editors. 2011, Springer: New York, NY. p. 201-224.

20. Fang, Z., A review of research on teacher beliefs and practices. Educational research, 1996. 38(1): p. 47-65.

21. Reybold, L.E., Pathways to the professoriate: The development of faculty identity in education. Innovative Higher Education, 2003. 27(4): p. 235-252.

22. Charmaz, K., Constructing Grounded Theory. 2nd ed. 2014, Los Angeles, CA: Sage.

23. Thomas, D.R., A general inductive approach for analyzing qualitative evaluation data. American journal of evaluation, 2006. 27(2): p. 237-246.

24. Seemiller, C., \& Murray, T. (2013). The common language of leadership. Journal of Leadership Studies, 7(1), 33-4. 